\title{
Assessing knowledge and attitudes of staff towards breastmilk for preterm infants as part of the PRIME (PReterm Infants need Milk Early) initiative
}

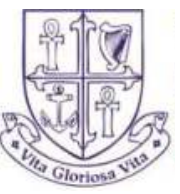

\author{
Dunne $E^{1}$, Murphy MC ${ }^{1}$, McCarthy $\mathrm{R}^{1}$, O'Hagan L1', Batson $\mathrm{H}^{1}{ }^{1}$ Curley $\mathrm{A}^{1}$
}

${ }^{1}$ National Maternity Hospital, Holles Street, Dublin 2, Ireland

\section{Background/Aims:}

Benefits of breast milk (BM) for preterm infants include a reduced risk of necrotizing enterocolitis (NEC) and sepsis. Our aim was to evaluate the knowledge and attitudes of staff towards BM for preterm infants as part of a QI project promoting early BM for these preterm infants.

Design/Methods:

- Cross-sectional survey study

- Tertiary maternity hospital, Jan - Feb 2018

- Anonymous questionnaire; data analysed with SPSS Results:

- 100 staff completed survey (Figure 1)

- All agreed BM important for preterm infants

- $47 \%$ felt confident assisting with hand expressing

- Less than half (45\%) felt that mothers should express within 2 hrs of delivery; $13 \%$ responded $12-24$ hrs
- Majority (61\%) responded that mothers should express 8-10 times daily; 17\% thought 4-6 times sufficient

- When asked what was most helpful to promote milk supply following delivery, $67 \%$ reported expressing milk; $33 \%$ reported rest/fluids

- $48 \%$ reported prevention of NEC as a reason that $\mathrm{BM}$ is important for preterm infants

- $51 \%$ satisfied with the current training provided

\section{Conclusion(s):}

- This survey illustrates the knowledge and attitudes towards BM for preterm infants in our hospital; these results informed a teaching program

- PRIME focuses on delivering consistent messages, to both parents and staff, for optimising early BM supply for preterm infants: 7 key messages for the first 7 days
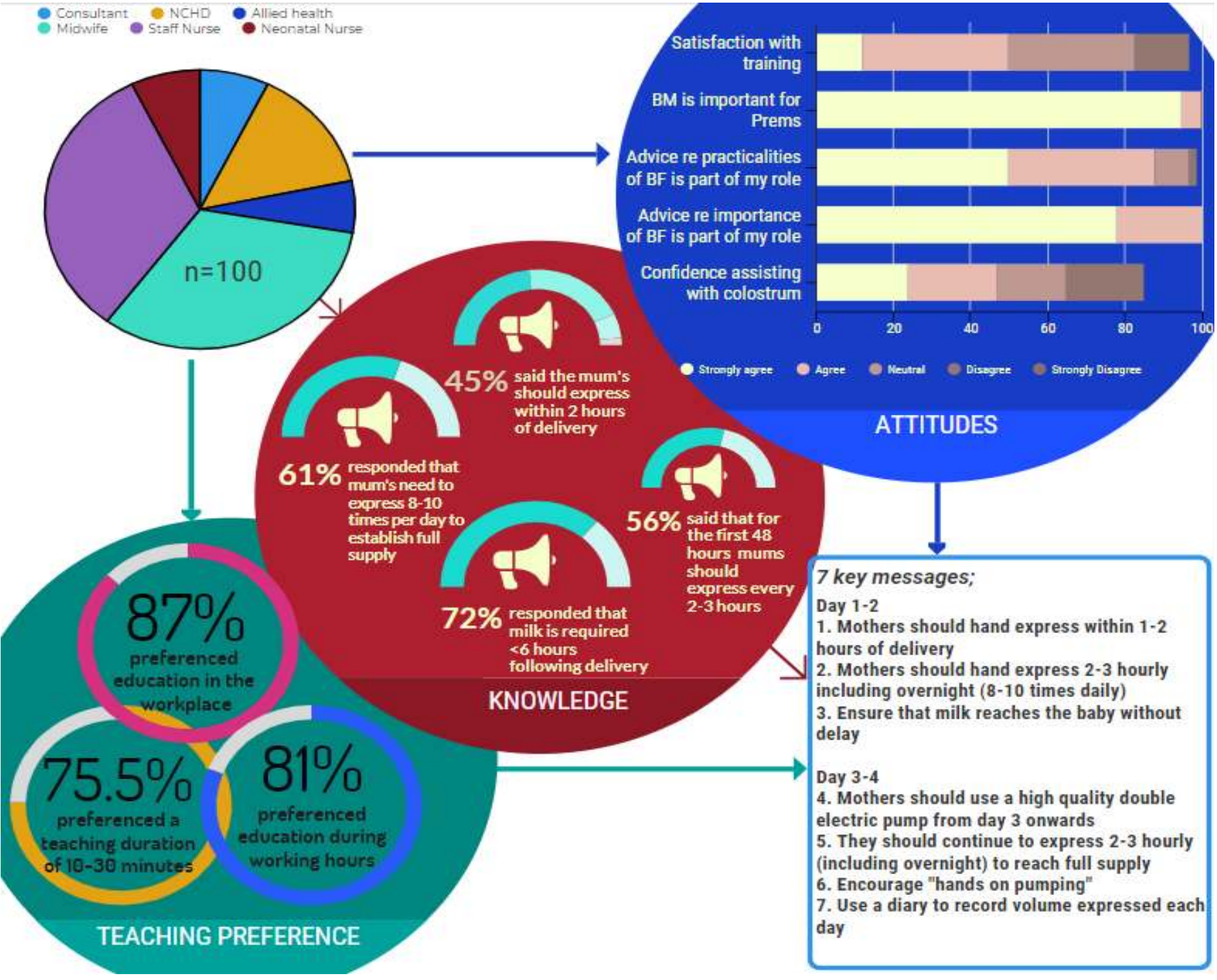